Leading Article

\title{
Spiritual care training and the GP curriculum: where to now?
}

\section{Alistair Appleby, General Practitioner, Aviemore Medical Practice, Aviemore, Inverness-shire, Scotland. John Swinton, School of Divinity, History and Philosophy, King's College, University of Aberdeen, Aberdeen, Scotland}

Philip Wilson, Centre for Rural Health, Institute for Applied Health Sciences, University of Aberdeen, Aberdeen, Scotland

Recent work exploring GPs' attitudes to spirituality and spiritual care reveals that we are in an interesting period of development. Guidance from a range of sources including the UK National Health Service and the General Medical Council encourages person-centred approaches to spirituality and recognition of patients' spiritual dimension and concerns.(1-3).

However, although professional guidance goes some way to outlining what is recommended it is becoming clear that although most GPs think that spirituality is meaningful and important to general practice, many are unclear about what this term means and feel inadequately trained when it comes to applying it(4).

Moreover, research concerning how spirituality is understood and applied by GPs demonstrates considerable variations: from a tendency to invalidate spiritual concerns by changing the subject, to active engagement in philosophical or theological dialogue or reflection. Between these polarities there is a good deal of pragmatic practice and GPs in previous studies show a strong desire to focus on patients' needs. However it is clear that GPs are not providing a service for patients which reflects a common set of competencies (5). Set against this are studies which suggest patients have varying expectations of spiritual care from doctors but, on the whole would like greater recognition of this aspect during healthcare. However, not all patients welcome doctors as "spiritual carers" and GPs who attempt to explore spiritual factors may sometimes risk disrupting their relationship with the patient or face criticism $(6,7)$.

A number of the GPs in the "Signed up or Souled out" study report a willingness to be involved in spiritual aspects of care, but then state that they tend not to discuss these aspects with patients. This finding, along with unpublished data from our previous studies demonstrates that GPs are failing to provide the level of spiritual, or perhaps more widely holistic care, which they aspire to. This finding supports the existence of an "attitude-practice gap". Our study confirms that personal qualities, affiliations and attributes of GPs affect attitudes to spiritual care, and may potentially define or limit the nature and scope of spiritual discussions with patients (8). This may reflect a lack of training, or the failure of training which is offered. Spiritual care approaches may be more than the possession of information or the application of standard consulting techniques, and arguably may entail both philosophical analysis and personal awareness. It may be challenging to represent this type of learning in orthodox curricular statements or to deliver it in clinical learning environments.

\section{The state of training}


Although limited work has been done to investigate the position of spirituality in undergraduate medical curricula $(9,10)$ the findings rely on the reporting of educational providers rather than the views or competencies of learners. These studies suggest that although $59 \%$ of UK medical schools claim to provide training in spirituality only around a third make this compulsory. In the US $90 \%$ of medical schools report providing spirituality training, but this was largely delivered in non-compulsory and unmeasured forms, as part of other areas of the curriculum. In only $7 \%$ was this specific and compulsory. Attempts to define what training in spirituality means, or looks like in practice may also be underdeveloped in primary care with the possibility that training in related disciplines, such as nursing, is more advanced (11).

At postgraduate level, appeals to reference patients' spirituality, and to understand the links between spirituality and health, appear in multiple GP and family practice curricula, including American, Australian and, more extensively, UK curricula. In the Royal College of General Practitioners' curriculum, spirituality appears in three areas: Core competency, End of Life Care, and Mental Health. The requirements include an awareness of cultural, religious and spiritual dimensions of health. Indicators of good practice include: "...... Interpret(ing) each patient's personal story in his or her unique context, considering the effects of additional factors that are known to influence an individual's health needs, including spiritual and other existential factors."

Additionally, GPs are called on to engage in personal awareness of their own beliefs and values in order to understand how these affect the nature of interactions with patients. "There will be cultural (including religious) differences between you and many of your patients. Your own values, attitudes, and feelings are important determinants of how you practice medicine." (12)

The ability to reflect on one's values, including one's spiritual, religious or secular background and beliefs, and interpret what they mean for patient care may include exploring philosophical, cultural and perhaps theological concepts and language which are currently alien to the environment of medical education. Additionally, this type of reflection and growth may be dependent on a unique environment of safety and trust which medical education may not have achieved.

\section{Is training really helping?}

Far from construing their medical training to promote competency in dealing with spiritual issues, some GPs in a recent Danish study reported that medical training may actually impair this, through a process of enculturation into a dominant secular medical paradigm(13). Among others we have suggested that there are more general difficulties in the relationship between the humanities and medical science. It is possible that medical training may rely on an approach which has done too little to adapt to contemporary movements in the philosophy of science (14). There is a cogent argument that an alternative philosophy of science is necessary for delivery of aspects of medical care (15), for understanding spirituality more generally(16) and for spirituality education in particular (17). What does seem clear is that the insertion of spirituality modules into curricula will be ineffective if what is implied by the general paradigm of medical training fatally undermines the possibility of an integrated approach to science and the 
humanities. As Dennet states "There is no such thing as philosophy-free science; there is only science whose philosophical baggage is taken on board without examination"(18).

In this respect the Royal College of General Practitioners' curriculum itself may be unhelpful, by creating philosophically polarised accounts. In statements on holistic care it suggests an approach which "acknowledges objective scientific explanations of physiology, but also admits that people have inner experiences that are subjective, mystical and, for some, religious, which may affect their health and well-being". A hard border between "scientific and objective" and "experienced and subjective" is increasingly disputed by some contemporary philosophers of science, and may be particularly inadequate for the human sciences(19). Thus, training for effective spiritual care may require cultural and philosophical upheaval in medical training, but this may already be overdue in other respects.

One potential answer to these conundrums would be to accept that spirituality is not a concept or area of care for which GPs are competent, and consequently to dismiss claims to provide a spiritual aspect to care. A second option would be to modify training to enhance this capability. Thirdly we could accept differing capabilities and more clearly define basic and gold standards of competence. These solutions are not mutually exclusive. It may be better to admit failure to do something, even something important, than make false claims to competency. Extension of chaplaincy, use of third partly providers, in-practice referrals and explorations of patients' unrecognised resources may assist in dealing with these variations in care. This does rely on GPs' perceptions or recognition of spiritual/existential need or distress. This recognition itself currently varies widely (20).

\section{Where now?}

The time is ripe both for deep reflection on the current failures of medical education to deliver training adequate for spiritual care, and to review claims to competency. It may be best not to rush in and tune up the existing system or to bolt on hastily produced modules delivered by clinicians. We need to live a little longer with the insight that something more general about medical education may prejudice spiritual care for our patients.

Reform may include investigating what type of experience or learning may modify spiritual care competencies. There is good evidence to suggest that early exposure to self and group reflection and transformative learning approaches, such as those of Mezirow or Freire, where the focus is on personal maturation and growth (praxis), could usefully be explored in this respect. (17) We suggest four key elements that are important in understanding where spirituality training is positioned in medical learning.

1. Examine what type of learning or experience fosters an ability to recognise, respect and engage with spiritual aspects of patient care, if this is considered desirable. Since the abilities which seem to be important are often personal, informally gained and related to the doctor's own stance on spirituality, transformative learning approaches may be promising. 
2. Recognise openly the current limitations and variations of GPs approaches to spirituality, and more clearly define what constitutes accepted and gold standards.

3. Admit that current training programmes may need conceptual and cultural reform, particularly in respect of a more integrative philosophy of science which supports a nondualistic approach to medicine and the humanities. We join others $(14,15)$ in suggesting critical realism $(19,21)$ has potential.

4. Consider whether Integration of spirituality training into existing clinical teaching should take place at an early stage, rather than relying on the current mainstream practice of elective or standalone voluntary modules.

Not acting means we must live with the current situation : of many GPs trying, but often failing to provide something they feel is important, for patients who are variably receptive, against a cultural training background which is outwardly supportive, but implicitly prejudicial to the endeavour.

Alistair Appleby (D)http://orcid.org/0000-0003-3206-9523

John Swinton D http://orcid.org/0000-0002-3991-8949

Philip Wilson (Dhttp://orcid.org/0000-0002-4123-8248

References

1. spiritual.care@nes.sco.nhs.uk. Spiritual Care Matters - An Introductory Resource for All NHS Scotland Staff [Internet]. 2017 [cited 2018 May 24]. Available from: http://www.nes.scot.nhs.uk/education-and-training/by-discipline/spiritual-care/aboutspiritual-care/publications/spiritual-care-matters-an-introductory-resource-for-all-nhsscotland-staff.aspx

2. Good medical practice [Internet]. [cited 2018 May 24]. Available from: https://www.gmcuk.org/ethical-guidance/ethical-guidance-for-doctors/good-medical-practice

3. End of life care for adults | Guidance and guidelines | NICE [Internet]. [cited 2018 May 24]. Available from: https://www.nice.org.uk/guidance/qs13/chapter/Quality-statement-6Holistic-support-spiritual-and-religious

4. Appleby A, Swinton J, Bradbury I, Wilson P. GPs and spiritual care: signed up or souled out? A quantitative analysis of GP trainers' understanding and application of the concept of spirituality. Educ Prim Care. 2018 Oct 19;0(0):1-9.

5. Appleby A, Swinton J, Wilson P. What GPs mean by "spirituality" and how they apply this concept with patients: a qualitative study. BJGP Open. 2018 Apr 17;bjgpopen18X101469.

6. Best M, Butow P, Olver I. Do patients want doctors to talk about spirituality? A systematic literature review. Patient Educ Couns. 2015 Nov;98(11):1320-8. 
7. Pujol N, Jobin G, Beloucif S. 'Spiritual care is not the hospital's business': a qualitative study on the perspectives of patients about the integration of spirituality in healthcare settings. J Med Ethics. 2016 Aug 24;medethics-2016-103565.

8. Vermandere M, De Lepeleire J, Smeets L, Hannes K, Van Mechelen W, Warmenhoven F, et al. Spirituality in general practice: A qualitative evidence synthesis. Br J Gen Pract. 2011;61(592):e749-60.

9. Neely D, Minford EJ. Current status of teaching on spirituality in UK medical schools. Med Educ. 42(2):176-82.

10. Koenig HG, Hooten EG, Lindsay-Calkins E, Meador KG. Spirituality in Medical School Curricula: Findings from a National Survey. Int J Psychiatry Med. 2010 Dec;40(4):391-8.

11. McSherry W. The principal components model: a model for advancing spirituality and spiritual care within nursing and health care practice. J Clin Nurs. 2006 Jul;15(7):905-17.

12. Core capabilities and competences [Internet]. [cited 2018 Sep 3]. Available from: http://www.rcgp.org.uk/training-exams/training/gp-curriculum-overview/onlinecurriculum/1-being-a-gp/core-capabilities-and-competences.aspx

13. Elisabeth Assing Hvidt, Jens Søndergaard, Dorte Gilså Hansen, Pål Gulbrandsen, Jette Ammentorp, Connie Timmermann, Niels Christian Hvid. 'We are the barriers': Danish general practitioners' interpretations of why the existential and spiritual dimensions are neglected in patient care. Commun Med. 2017;14(2).

14. Pilgrim D. The Biopsychosocial Model in Health Research: Its Strengths and Limitations for Critical Realists. J Crit Realism. 2015 Apr 1;14(2):164-80.

15. Cruickshank J. Positioning positivism, critical realism and social constructionism in the health sciences: a philosophical orientation. Nurs Inq. 2012 Mar 1;19(1):71-82.

16. Losch A. Critical Realism-A Sustainable Bridge Between Science and Religion? Theol Sci. 2010 Nov 1;8(4):393-416.

17. Mthembu, T.G, Wegner, L., Roman, N.V. Educators' and students' needs regarding teaching and learning strategies for integrating spirituality and spiritual care in occupational therapy education. Afr J Phys Act Health Sci. 2018 Jun;24(2):127-42.

18. Dennet D. Darwins Dangerous Idea. Penguin books, London; 1995.

19. Bhaskar R. The Possibility of Naturalism: A philosophical critique of the contemporary human sciences. 4 edition. London; New York: Routledge; 2014. 238 p.

20. Appleby A, Swinton J, Wilson P. 'I'm not sure if there is any point to all this doc?': a qualitative study into GPs responses to existential questions. Br J Gen Pr. 2018 Jun 1;68(suppl 1):bjgp18X697061. 
21. Bhaskar R. A realist theory of science. 1st ed. Oxford, UK: Routledge; 2008. 